\title{
Modeling and Analysis of Pollution-Free Agricultural Regulatory Based on Petri-Net
}

\author{
Fang Wang, Qingling Duan", Lingzi Zhang, and Guo Li \\ College of Information and Electrical Engineering, \\ China Agricultural University, Beijing, P.R. China 100083 \\ dqling@cau. edu.cn
}

\begin{abstract}
To carry out pollution-free agricultural products certification work is the important issue of people's daily lives. It is of great significance to construct the pollution-free agricultural regulatory system (PFARS) and achieve the office automation of the certification business. However, the PFARS contains much more steps in dispersion areas that it is very complex for business processes of E-PFAPC. In this paper, we not only provide the method of modeling the PFARS with Petri Net, but also provide the improved method to analysis the Performance of the constructed workflow model. The model for the PFARS provides a more simply process management than original work method. The provided workflow model analysis method can effectively verify the performance of building model. The results show that the PFARS system constructed by the workflow model can implement the business run automatically and own prefect performance.
\end{abstract}

Keywords: workflow, pollution-free agricultural products, Petri net, work flow model, equivalent simplification, model performance.

\section{Introduction}

Pollution-free agricultural products is the production that area, production process and product quality meet the national requirements of the relevant standards, Obtain a certificate and allow use the sign of pollution-free agricultural products [1]. Currently, the pollution-free agricultural products certification used in turn by the county, Agency-level work, provincial, sub-centers, the center of Ministry, and all other working bodies for approval step by step. But the information and instruments which used during the Certification at all levels of agency transfer by Postal service. This manual method is not only cost a lot of manpower, financial resources but also time. And can not do government affairs. Therefore, the design and development of electronic control systems is the trend of pollution-free agricultural products. One of the

\footnotetext{
* Corresponding author.
} 
key technologies to achieve the system is how to achieve pollution-free agricultural systems certification information automatable transfer during at all level of work agencies. The workflow technology leaded into the PFARS can solve the problems. Workflow technology according to the system real operational rules can make certified information fully or partially run automatically, in order to make the documents, information or tasks in business processing can automatic transfer and implement [2].

Model is the most important elements to determine the quality of workflow system. In this paper, we use the Petri Net which has a strict mathematical basis for pollution-free agricultural products regulation system workflow model to described certification business behavior, and an improved model method to verify the performance of the model.

\section{Pollution-Free Agricultural Regulatory System Modeling}

\subsection{Petri net Technology and Work Flow Model}

Petri net invented by Carl • A • Petri in the 1960s [3], is a parallel system of discrete mathematics, suitable for describing asynchronous, concurrent computer system model. Petri nets can be graphically described the workflow, and own standard, clear and rich analysis techniques, to avoid ambiguity, uncertainty and contradiction. This method is one of the most common methods to construct the workflow model.

Petri net is a two-way map that consisted by Place, Transition and the relation between them.

Definition 1: A Petri net is a necessary and sufficient conditions to satisfy the following triple $\mathrm{N}=(\mathrm{P}, \mathrm{T}, \mathrm{F})[3]$.

(1) $P \cup T \neq \varnothing($ Net of non empty);

(2) $P \cap T=\varnothing$ (Duality);

(3) $F \in(P \times T) \cup(T \times P)$ (Flow relation only between the Place and Transition);

(4) $\operatorname{dom}(F) \cup \operatorname{cod}(F)=P \cup T$ (Not isolated elements). Where $\operatorname{dom}(\mathrm{F}), \operatorname{cod}(\mathrm{F})$, respectively on behalf of the domain and range.

The structure of a Petri net elements include: place, transition and the arc. Place used to describe the possible local state (condition or status). Transition describes the events which modified state of the system. Arc is the relationship between place and transitions. 
Workflow model is the basis for workflow management systems. Workflow model the abstract and refine of the actual business processes, is the idea of workflow and workflow terms of the business process description and modeling results [4].

Workflow model includes all information which can execute by workflow engine, the information contains the condition to start or end a business process, the flow relation of the control data, Participants, organization, data, the application may be invoked, and all definition data which relevant to workflow. Workflow model consisted by two basic elements there are nodes and connecting, which is defined as a directed graph $W \in\{N, L\}, \mathrm{N}$ is the node set, $\mathrm{L}$ is the set of arc connections between nodes. In workflow model node stands for all activities, which refers to the general work unit. Each activity is independence and has its own properties. Examples of activities are task, for different process instance, the same activities may have different tasks.

In the design of pollution-free agricultural products certification business workflow model is not only to describe the workflow process model, but also describe the certification body of the organization model, resource model, and provide information related to the definition of workflow data to make it a complete, multi-view of the model [5]. Process models are referenced by organized model, workflow relevant data and resource model. Workflow relevant data to support process model, organization model and resource model. The relationship between system models as shown in Figure 1:

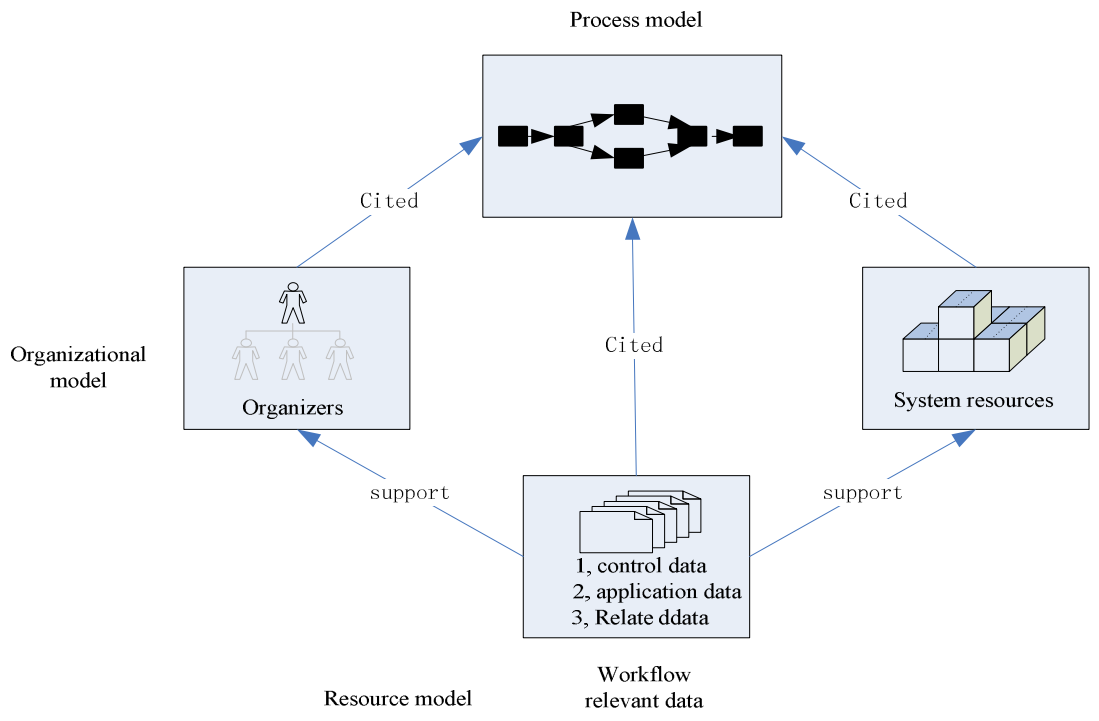

Fig. 1. Certified pollution control system model diagram 


\subsection{The Pollution-Free Agricultural Products Certification Net Model}

In system, organizational model consists of five elements: "staff", "role", "post", “department" and "working group." The relationship of the Organizational model shown in Figure 2:

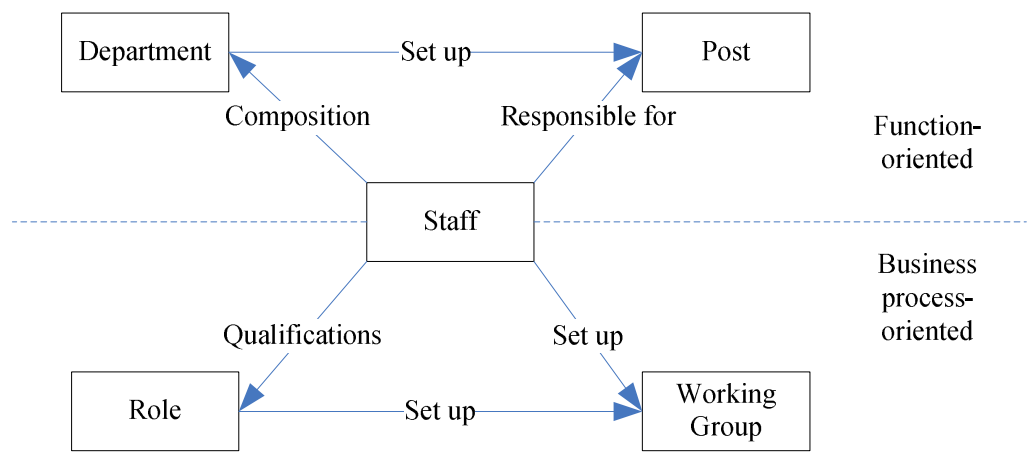

Fig. 2. Organization Model Entity Relationship Diagram

(1) Staff: Staff is the basic elements of the model which directly attributable to a certain department or working group. Each officer can own different role according his responsibilities or positions, and each role also corresponds to one or more human.

(2) Department: is set for functions. In general, department is a agency which has the same location, goal and task. In addition to personnel other than, the other entities in system is a sub-level tree structure layer by layer.

(3) Position: according to different responsibility in the sector to division different positions. Positions have the relationship formed between the upper and lower levels, staff responsible for the responsibilities of the position.

(4) Role: is process-oriented and established based by the division of tasks in the system. Only with the role of staff have the appropriate permissions to operate.

(5) Working Group: In order to adapt change or other tempt need, human in different departments and different roles can be organized dynamically. The Working Group was established for the process, reflecting the traditional function-oriented organization.

The work organizations of the Pollution-free agricultural regulatory system are all over the country. As shown in Figure 3: 


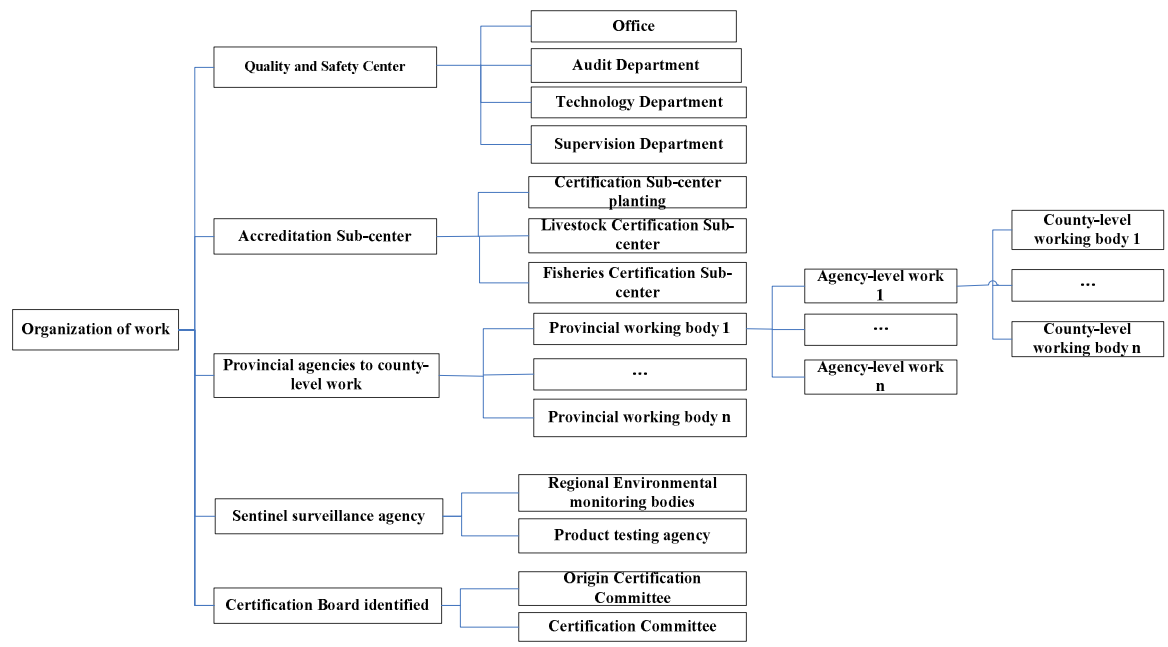

Fig. 3. System of work organization

In the pollution-free agricultural regulatory systems, according to certified business processes into the role of the Ministry Center, the role of sub-central, the role of three types of local certification.

(1) Central role of the Department

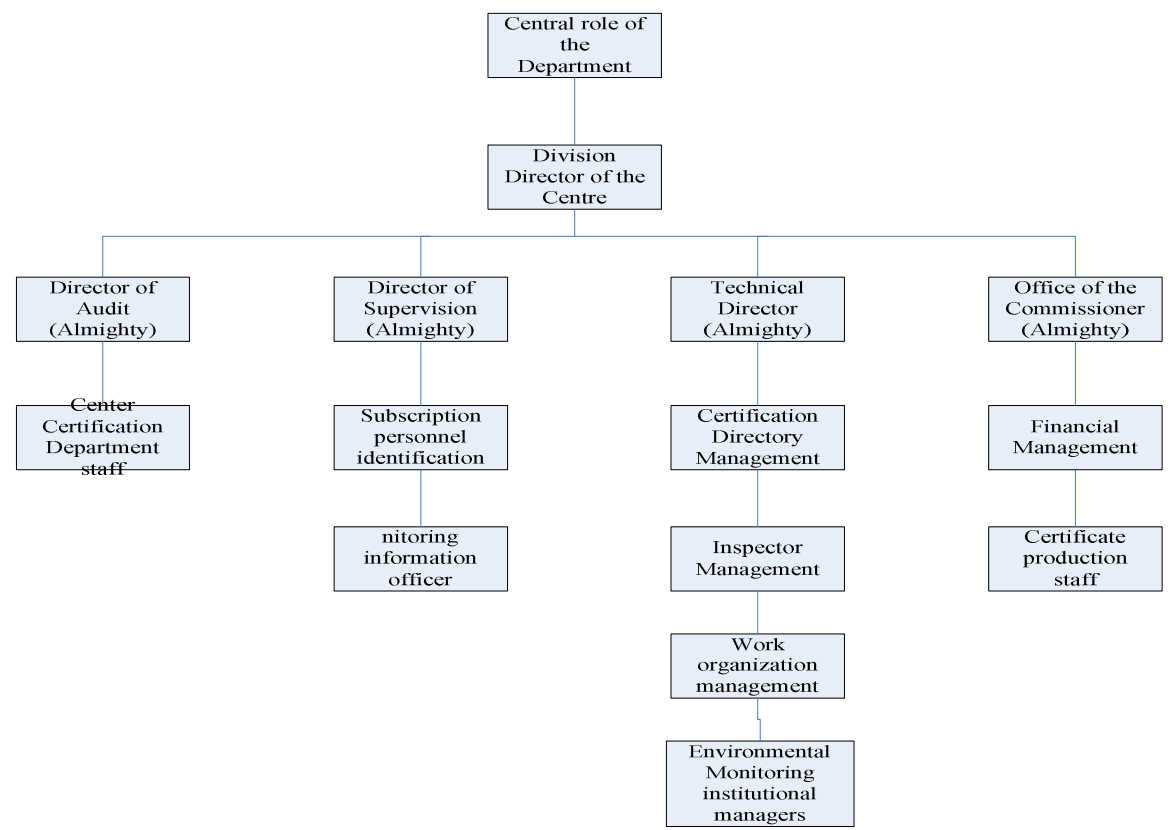

Fig. 4. Ministry of Agriculture, Centre for quality and safety role model 
(2) Sub-center role of the Accreditation

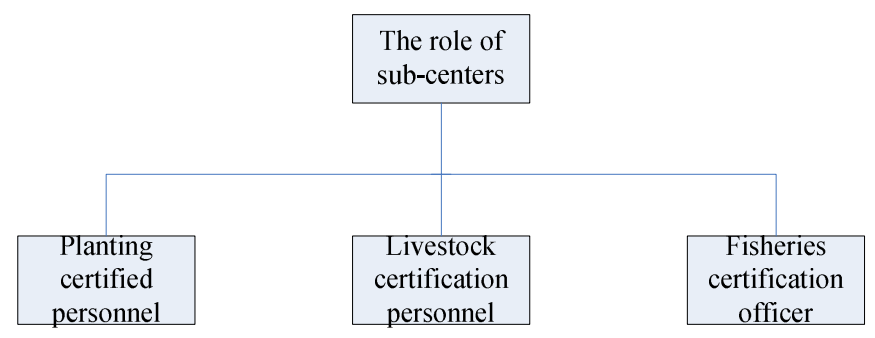

Fig. 5. Role model professional certification sub-centers

(3) Local certification role

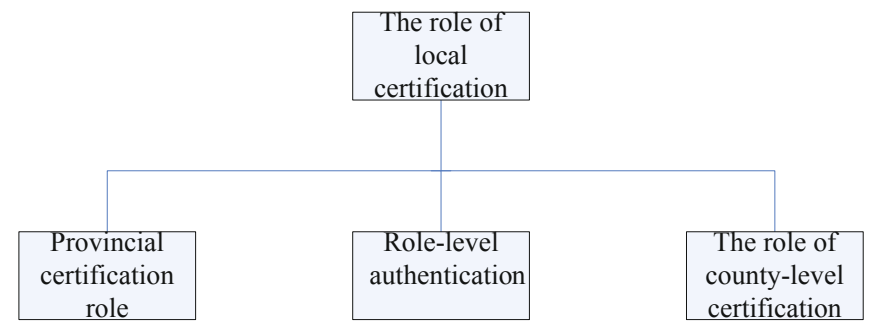

Fig. 6. Local certification role model

Pollution-free agricultural regulatory systems certification business lines include: the first certification, Extended Authentication, normal replacement and portable review replacement. Each certified business requires approval through their respective links, materials review, site inspection, product inspection, origin detection, environmental testing and other relevant certification steps. Petri net based workflow process model is the abstract representation of the actual business processes, that is, the abstract representation of the business process. Based on the analysis of pollution-free agricultural products certification based on business processes, were established the first certified pollution, widening the certification, the normal review replacement, portable replacement and certificate review workflow process model change, where "O" stands for Place, " $\square$ " on behalf of Transition. To pollution-free for the first time the following certification business, for example, use of Petri net technology to build a workflow process model. First certification workflow process model shown in Figure 7: 


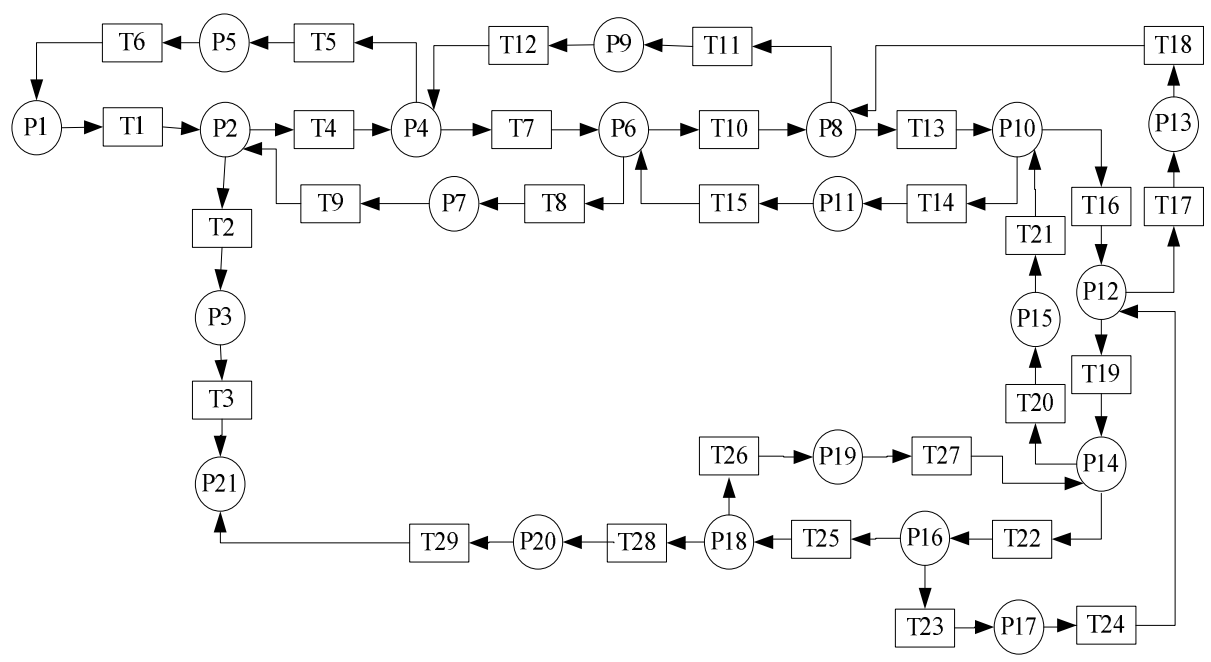

Fig. 7. Petri net-based breadth-first number of the first successful business model certification

The figure shows the first pollution-free agricultural regulatory systems certification business workflow model, taking into account the requirements model that will change in the original image and the place are carried out in accordance with the breadth-first order number, which used place $\mathrm{T} 1, \mathrm{~T} 2, \ldots \ldots$, said that change with the $\mathrm{P} 1, \mathrm{P} 2, \ldots \ldots$ said.

Figure in the place are the following meanings: T1 representation review audit, T2 that do not pass a formal examination, T3 that do not fill in the form of review of information through the comments, T4 confirmed that compliance approval, T5 that approval be returned to confirm compliance, T6 that fill approval to return to confirm the views of compliance information, T7, said approval to appoint inspectors, T8, said approval to appoint inspectors to return processing, T9 complete approval to appoint inspectors to return views of information, T10, said a comprehensive inspection approval, T11 comprehensive examination that approval be returned, T12 that a comprehensive examination of information processing views of complete return, T13 found that approval of origin, T14 found that approval of origin return processing, T15 found that approval of origin information filled returned opinions, T16 preliminary approval of products, T17 preliminary approval that products be returned, T18 Product preliminary approval, said approval of the views of complete return information, T19 review for approval of products, T20 review for approval of products be returned, T21 complete return of products to review for approval the views of information processing, T22 that generate batch processing, T23 that approval be returned batch generation, T24 fill in return for approval, said approval of the batch generation views information, T25 Final review of products, T26 Final review that product be returned, T27 Final return products that fill in the information processing view, T28 review that certificate number generated by, T29 reported that approval document signed audit through. 


\section{Model Performance Analysis}

Traditional network based on Petri workflow process model built performance analysis method has exponential time complexity, based on pollution-free agricultural products certification process certified business link in task completion time of uncertainty, assumptions in the certification process to prepare an adequate prerequisite for certification material condition cases, pollution-free agricultural products certification based on drift-nets, stochastic Petri net equivalent simplification approach can introduce random trigger Petri-Net, we propose a linear time complexity of the average running time of workflow approximate performance analysis method, to make the capabilities of the model more precise analysis of time performance.

In the continuous-time stochastic Petri net, a change can be implemented from time $t$ to the implementation of the delay between the time seen as a continuous random variable, subject to $\mathrm{A}$ as a parameter of exponential distribution. A $\mathrm{t}$ is the average implementation rate of change that can be implemented in the case of the implementation unit of time the average number. The reciprocal of the average implementation rate of $1 / 2$ as changes $t_{0}$, is the average implementation delay or average service time.

Combined with pollution-free agricultural products certification nets in the certification business for the execution time of the exponential distribution, the model of relief activities $T_{i}$, where $(1 \leq \mathrm{i} \leq \mathrm{n})$ associated with a rise rate $\lambda_{t}$, which $\lambda_{t}$ is greater than 0 , the real parameter, and A certified business for $\mathrm{T}$ to become enabled from time to time between it being raised as a continuous random variable $X_{\mathrm{i}}$ (to take a positive real number), and subject to a distribution function $F_{t}(x)=\left\{X_{t} \leq x\right\}$, the n random variables $\mathrm{X}_{\mathrm{i}}(1 \leq \mathrm{i} \leq \mathrm{n})$ as independent random variables. The distribution function can be defined as an exponential distribution function: $F_{t}(x)=1-e^{-\lambda x}(\forall t \in T)$ that the random variable $X_{\mathrm{t}}$ parameters obey the $\lambda_{t}$ exponential distribution.

According to the equivalent Petri Net reduction rules, pollution-free certification model simplified model shown in Figure 8:

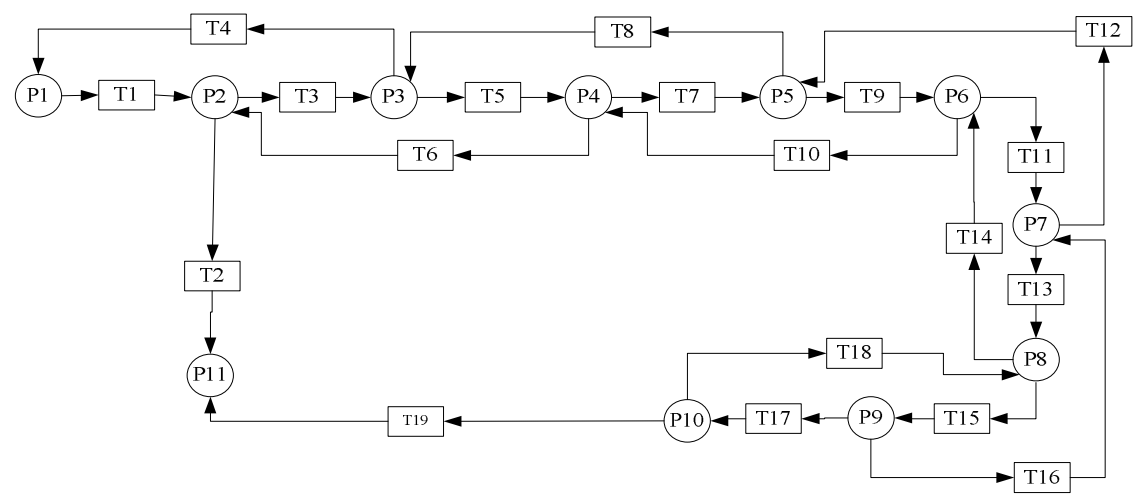

Fig. 8. The Simplified workflow model of the first time Pollution-free certification business 
Theorem $1: t_{1} \rightarrow t_{2} \rightarrow \cdots t_{i} \cdots \rightarrow t_{n}$ that certification part of the business activities of changes in $t_{i}$, order execution, time to change the equivalent rescue execution time t: $\frac{1}{\lambda}=\sum_{i=1}^{n} \frac{1}{\lambda_{i}}$.

Certification activities in the above definition changes $t_{1}, t_{2}, \ldots \ldots, t_{n}$ cause of the time independent random variables $\lambda_{1}, \lambda_{1}, \lambda_{2}, \cdots, \lambda_{n}$ and follows a command parameter of Exponential distribution, $\mathrm{n}$ translation the execute time were to $\frac{1}{\lambda_{1}}, \frac{1}{\lambda_{2}}, \cdots, \frac{1}{\lambda_{n}}$; Use a time change $\mathrm{t}$ stands for $\mathrm{n}$ missions composed of the same subnet, the average service time $\mathrm{T}\left(\frac{1}{\lambda}\right)$.

According to the actual certification of pollution combined with expert opinion, statistics Figure 8 the various certification business for the time $t_{\alpha}\left(\frac{1}{\lambda_{1}}\right)=20 \mathrm{~m}$, county-level review by the time the work of institution-level audit time $t_{\alpha}\left(\frac{1}{\lambda_{2}}\right)=35 m$, the provincial work plan review time $t_{\alpha}\left(\frac{1}{\lambda_{3}}\right)=40 m$, review time of sub-centers $t_{\alpha}\left(\frac{1}{\lambda_{4}}\right)=35 m$, the Department of center when the audit $t_{\alpha}\left(\frac{1}{\lambda_{5}}\right)=56 m$

After simplifying the workflow process model, mainly composed by the sequence structure. Change $\mathrm{t} 1, \mathrm{t} 3, \mathrm{t} 5, \mathrm{t} 7, \mathrm{t} 9, \mathrm{t} 11, \mathrm{t} 13, \mathrm{t} 15, \mathrm{t} 17, \mathrm{t} 19$, constitute the order structure $\left(t_{1} \rightarrow t_{3} \rightarrow \cdots t_{i} \cdots \rightarrow t_{19}\right)$. Change $\mathrm{t} 1$ which constitute part of county-level certification; change $\mathrm{t} 3, \mathrm{t} 5, \mathrm{t} 7$, constitute part of prefecture-level certification; change $\mathrm{t} 9, \mathrm{t} 11$, constitute part of the provincial certification; changes 113 certification form part of sub-centers; changes t15, t17, t19, constitute the Department of Center Certification link; know that normally the average processing time is: $405 \mathrm{~m}$, largely for the certification of agricultural products now save time and money.

\section{Conclusion}

This paper proposes a method to construct the first pollution-free agricultural products certification through use of Petri-net by analysis the actual requirements of the pollution-free agricultural regulatory operations and study the techniques of the workflow modeling. The model can clearly describe the certification business processes, lay a good foundation for the stable operation of the system. 
Moreover, to prove the performance of the workflow model, proposed the model reduction and stochastic Petri nets combination of authentication methods. By study the model verify that it is applied to the feasibility of pollution-free agricultural regulatory system can improve efficiency, government affairs, information sharing.

The system is currently in trial operation phase, the performance is steady; apply to the country of five pollution-free agricultural regulatory agencies to jointly monitor the actual business process management needs.

\section{References}

1. Maaiguo, J., Luobin, F.: Pollution-free agricultural management and technology. China Agriculture Press, Beijing (2007)

2. Wang, G.: Workflow-based-e-government system and implementation of [MS Thesis]. Beijing Jiaotong University, Beijing (2007)

3. Yuan, C.: Petri Net Theory and Applications. Electronic Industry Press, Beijing (2005)

4. Jiang, C.: The behavior of Petri net theory and its applications. Higher Education Press, Beijing (2003)

5. van der Aalst, W.M.P., van Hee, K.M., van der Toom, R.A.: Component-based software architectures:a framework based on inheritance of behavion BETA Working Paper Series, WP 45, Eindhoven University ofTeclmology,Eindhoven (2000)

6. Dong, M., Chen, F.F.: Process modeling and analysis ofmanufacturing supply chain networks using object-oriented Petri nets. Robotics and Computer Integrated Manufaentring 17, 121-129 (2001)

7. Browning, T.R., Eppinger, S.D.: Modeling impacts ofprocess architecture on cost and schedule risk in product development. IEEE Transactions on Engineering Management 49, 428-442 (2002)

8. van der Aalst, W.M.P., van Hee, K.M., van der Toom, R.A.: Component-based software architectures:a framework based on inheritance of behavion BETA Working Paper Series,WP 45,Eindhoven University ofTeclmology, Eindhoven (2000)

9. Morelli, M., D’Eppinger, S.D., Gulati, R.K.: Predicting technical communication in product development organizations. IEEE Transactions on Engineering Management 42, 215-222 (1995)

10. Karsten, A., Schulz Orlowsk, E.: Facilitating cross-organisational workflows with a workflow view approach. Data\&Knowledge Engineering 51, 109-147 (2004)

11. Workflow Management Coalition.Terminology and Glossary,[EB/OL].WFMC-TC 1011, pp. 3-8 (1999)

12. Workflow Management Coalition. Workflow Management Coalition Terminology and Glossary.Technical Report. WFMC-TC—1 01 1. Workflow Management Coaltion, Brussels, pp. 34-46 (1996)

13. Hollingsworth, D.: The Workflow Reference Model. WfMC-TC - 1003, Issue, Brussels, pp. 201-210. Workflow Management Coalition, Brussels (2004) 